\title{
Effectiveness of chronic care model-oriented interventions to improve quality of diabetes care: a systematic review
}

Damin Si and Ross Bailie Menzies School of Health Research, Institute of Advanced Studies, Charles Darwin University, Darwin, NT, Australia and Tarun Weeramanthri Northern Territory Department of Health and Community Services, Darwin, NT, Australia

\begin{abstract}
Background: The chronic care model (CCM) has been widely used in a variety of health care settings to guide system improvement for chronic illness care, including diabetes care. However, the evidence base for the specific components of the model has not been systematically reviewed. This review aimed at examining the extent to which interventions featuring the $\mathrm{CCM}$ components improve diabetes care and determining the relative effectiveness of different CCM components. Methods: We systematically searched MEDLINE (1966 to December 2004), the Cochrane Effective Practice and Organisation of Care and the Cochrane Controlled Trials Register to identify interventions featuring one or more system components of the CCM for diabetes care. Outcome measures included $\mathrm{HbA1c}$, blood pressure and blood lipid control. We used random-effects meta-analysis and meta-regression for quantitative synthesis of data. Results: In all, 69 studies (43 randomized controlled trials and 26 controlled before-after studies) met inclusion criteria and were included in this review. Overall, included studies reported a mean reduction of $0.46 \%(95 \% \mathrm{Cl} 0.38,0.54)$ in $\mathrm{HbA} 1 \mathrm{c}$, mean reduction of $2.2(95 \% \mathrm{Cl} 0.9,3.5) \mathrm{mmHg}$ in systolic blood pressure, mean reduction of $1.3(95 \% \mathrm{Cl} 0.6,2.1) \mathrm{mmHg}$ in diastolic blood pressure and mean reduction of $0.24(95 \% \mathrm{Cl} 0.06,0.41) \mathrm{mmol} / \mathrm{L}$ in total cholesterol. For specific $\mathrm{CCM}$ components, interventions that addressed delivery system design reported the largest improvements in patient outcomes, followed by those employing a selfmanagement support component. Interventions involving decision support or clinical information systems reported relatively smaller effect sizes. Conclusions: Interventions featuring CCM components for diabetes care produced small-to-moderate improvements in a range of patient intermediate outcomes. The findings support the concept of the CCM in which the state of development of various aspects of primary care service systems defined in this model appear to be important factors in the quality of care provided to people with diabetes.
\end{abstract}

Key words: chronic illness; diabetes; primary care; systematic review; systems

Received: April 2007; accepted: October 2007

\section{Introduction}

\section{Development of the chronic care model}

The chronic care model (CCM), a conceptual model for improving chronic illness care, was first

\footnotetext{
Address for correspondence: Damin Si, Menzies School of Health Research, Charles Darwin University, Casaurina, NT 0810, Australia. Email: damin.si@menzies.edu.au
}

described in an article published in 1998 by Wagner (1998). It was developed on the basis of an examination of literature which reported successful practice and system changes leading to improved chronic illness care, and on a consensus among experts (Wagner et al., 1996; 1999).

The CCM describes the interacting system components required for providing high-quality chronic illness care (see Figure 1). Within a health 


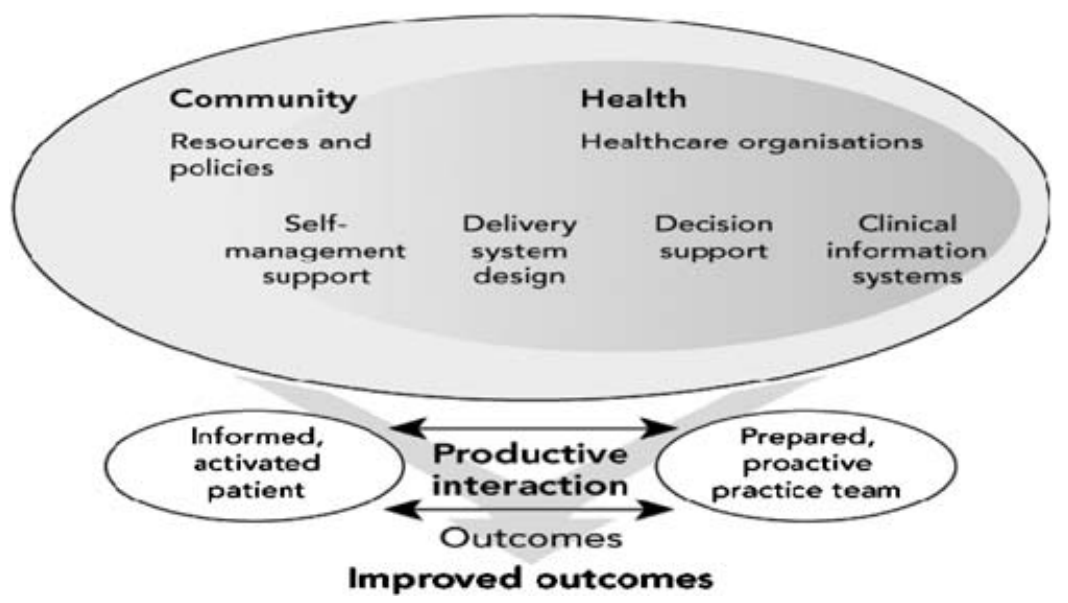

Figure 1 The chronic care model (CCM) (Wagner, 1998). Reproduced with permission from the American College of Physicians.

care system, there are four components at the practice level: self-management support, delivery system design, decision support and clinical information systems. A higher level component, organization of health care, plays an overarching role to guide practice-level development. A broader component, the community, provides necessary resources and policies linked to chronic illness care. The development and integration of these components is seen to foster productive interactions between prepared, proactive health providers and informed, activated patients. As a result, patients' outcomes are expected to be improved.

The CCM has gained considerable attention and has been used in a variety of health care organizations. In the United States, more than 100 health care organizations, including hospital systems, academic health centres and community health systems, have completed the national chronic condition quality improvement programmes using the CCM framework (Wagner et al., 2001a). In Canada, the CCM has been applied in the Capital Health Region of Victoria, British Columbia, to develop and evaluate a region-wide initiative to improve the outcomes of people with diabetes and those at risk of diabetes (Fulton et al., 2001). It was suggested that the CCM could help the National Health Service in the UK to focus on wider policies for generic chronic illness care, rather than implementation of service frameworks for selected chronic conditions (Lewis and Dixon, 2004). Furthermore, the CCM has been adopted and expanded by the WHO to develop an Innovative Care for Chronic Conditions framework, which serves as a basis for policy development and system redesign in global contexts (Epping-Jordan et al., 2004).

\section{Evidence base for the chronic care model}

Several published observational studies have demonstrated the implementation of the CCM in clinical practices and observed improved quality of care (Wagner et al., 2001b; Bonomi et al., 2002; Sperl-Hillen et al., 2004; Wu et al., 2003). However, these evaluations employed uncontrolled beforeand-after study designs, making it difficult to conclude whether the changes in patient care resulted from the interventions or from other un-measured factors. Two recently published experimental studies provide stronger evidence in support of CCMoriented interventions (Piatt et al., 2006; Landon et al., 2007). However, the generalizability of these two US-based studies is not clear. In addition to this relatively limited evidence base for explicitly CCM-oriented interventions, the impact of primary care system-oriented interventions relating to specific components of the CCM has been examined by many studies across the world. An attempt to systematically review the impact of such interventions in the context of diabetes care has been made by Bodenheimer et al. (2002). They re-analysed studies identified by a Cochrane review that assessed the effects of interventions 
targeting health professionals and the structure of care on diabetes management in primary health care (Renders et al., 2001). However, the scope designated in the CCM is broader than that covered by the Cochrane review, where some relevant studies might have been systematically excluded from the analysis by Bodenheimer. Another recent systematic review took a similar approach, but included impacts on a wide range of chronic disease outcomes (Zwar et al., 2006). The effectiveness of interventions across the scope of the CCM requires further study.

\section{Aims of this review}

1) To systematically identify studies of diabetes care that assess effects of interventions featuring the CCM components;

2) To examine the extent to which interventions featuring the CCM components improve diabetes care and

3) To determine the relative effectiveness of different CCM components on diabetes care.

\section{Methods}

\section{Criteria for selecting studies}

\section{Types of studies}

Two types of studies were included: randomized controlled trials (RCTs) and controlled before-and-after studies (CBAs). Inclusion of non-randomized controlled studies such as CBAs in reviews has been recommended by the Cochrane Effective Practice and Organisation of Care Group (2006), as many organizational and professional interventions may not be feasible to be evaluated in a RCT.

\section{Types of populations}

Participants in studies were required to meet the following three criteria:

1) Diagnosis of type 1 or type 2 diabetes;

2) Aged 16 years or more;

3) Non-hospitalized patients, who received care in a primary care, outpatient or community setting.

Studies that focused on gestational diabetes were excluded.

\section{Classification of interventions}

Studies included are those with interventions targeting organizational systems, management, professionals or patients using systematically developed approaches for diabetes care (detailed in Table 1). Studies aimed exclusively at evaluations of single treatment methods (eg, psychotherapy or specific drugs) and drug compliance studies were excluded. In line with the concept of the CCM, intervention components were classified into six categories (Table 1). In general, the control groups in included studies received 'usual care' or 'standard care'.

\section{Outcome measures}

Intermediate patient outcomes:

- HbA1c control;

- Systolic and diastolic blood pressure control;

- Blood lipid control (including total cholesterol, HDL, LDL and triglycerides).

We only included patient outcome data obtained by chart reviews, direct clinical examinations or through clinical information systems. Data from patient or provider self-reporting were excluded.

\section{Search strategy for identification of studies}

a) The following electronic databases were searched:

Cochrane Effective Practice and Organisation of Care (EPOC) specialized register, the Cochrane Controlled Trials Register (CCTR) (Cochrane Library Issue 2, 2005) and MEDLINE (1966 to December 2004).

We adapted search strategies recommended by the Cochrane Metabolic and Endocrine Disorders Group (2003), Cochrane Effective Practice and Organisation of Care (2004), and other Cochrane reviews (Giuffrida et al., 1999; Renders et al., 2001; Griffiths et al., 2005; Roger, 2004) (search strategy available on request from the authors).

b) References of published systematic reviews related to diabetes care.

We identified systematic reviews or metaanalyses related to diabetes care by searching two electronic databases in the Cochrane Library (keyword 'diabetes mellitus' was used): the Cochrane Database of Systematic

Primary Health Care Research \& Development 2008; 9: 25-40 
Table 1 Classification of interventions

\begin{tabular}{|c|c|}
\hline Intervention component & Feature \\
\hline Organizational influence ${ }^{a}$ & $\begin{array}{l}\text { - Organizational goals and resources for chronic illness care } \\
\text { - Quality improvement strategies } \\
\text { - Incentives }\end{array}$ \\
\hline Community linkages & $\begin{array}{l}\text { - Linking patients to outside resources } \\
\text { - Activities with community-based organizations } \\
\text { - Professionals working out in the community }\end{array}$ \\
\hline Self-management support & $\begin{array}{l}\text { - Interventions based on technological aids to promote self-care } \\
\text { - Self-help groups } \\
\text { - Family-oriented supports } \\
\text { - Motivational support } \\
\text { - Behaviour therapy }\end{array}$ \\
\hline Decision support & $\begin{array}{l}\text { - Practice guidelines } \\
\text { - Provider education } \\
\text { - Involvement of specialists in improving primary care }\end{array}$ \\
\hline Delivery system design & $\begin{array}{l}\text { - Practice team functioning } \\
\text { - Patient care planning and follow-up } \\
\text { - Coordination between primary care and specialist services }\end{array}$ \\
\hline Clinical information systems & $\begin{array}{l}\text { - Disease registry } \\
\text { - Reminders to providers } \\
\text { - Feedback to providers }\end{array}$ \\
\hline
\end{tabular}

a We use 'organizational influence' to replace the original term ' health care organizations' in the chronic care model (CCM). As 'health care organizations' and 'health care systems' are usually used interchangeably, our modification would allow the six components in the CCM to be termed logically as system components.

Reviews (CDSR) and Database of Abstracts of Reviews of Effects (DARE). Systematic reviews (or meta-analyses) with their aims related to any areas defined in Table 1 were retrieved to obtain their reference lists.

c) Reference list of each retrieved article was scanned to identify further studies.

\section{Review process and data abstraction}

Initially, all abstracts of studies identified by electronic and hand search were screened by a single reviewer (DS) against the inclusion criteria, to identify potential studies that merited full-text reviews. The author repeated this process to ensure the reliability for selection into the review. The full articles of all studies for which abstracts were identified as possibly meeting the inclusion criteria at either screening were retrieved for further assessment.

At the full-text level, a standardized abstraction form was used by the single reviewer to extract information on study characteristics, interventions,

Primary Health Care Research \& Development 2008; 9: 25-40 outcomes and design quality. For each study, the reviewer repeated the processes of classifying interventions and appraising study quality. Any discrepancies between the initial and repeat process were reviewed and resolved.

When a single study led to multiple publications, all relevant papers were reviewed together and one single form was used to collect data.

When a single study involved several intervention arms (versus a control arm), each pair of intervention and control arms was considered as a separate comparison. For example, if a study composed of three intervention arms and one control arm, three data abstraction forms were used for each of three comparisons.

Outcomes in each study, where possible, were reported in the following ways:

- Patient outcomes (HbA1c, blood pressure, total cholesterol, HDL, LDL and triglycerides): mean and standard deviation for each of the intervention and control arms before and after the intervention. 


\section{Quality assessment}

As part of data collection, quality assessment for each included study was conducted using a standardized assessment tool. The tool was developed by the Effective Public Health Practice Project (2006) and consists of six quality criteria:

- Selection bias

- Allocation bias

- Confounders

- Blinding of outcome assessors

- Data collection methods

- Withdrawals and dropouts

Each of these six criteria was rated as 'strong', 'moderate' or 'weak' in quality for a given study using predetermined standards. Each study also received an overall assessment of strong, moderate or weak quality by the following definition: (1) strong - at least four of six criteria were rated as strong, with no weak ratings; (2) moderate one criterion was rated as weak; and (3) weak two or more criteria were rated as weak.

\section{Statistical analysis}

Following the method employed in a recent systematic review of quality improvement strategies for diabetes care (Shojania et al., 2006), we calculated the effect size (and its standard error) for each single study using the following formulas:

- Effect size (mean difference $)=$ difference in postintervention values between intervention and control groups for mean patient outcomes. In this article, we simply state effect sizes for different patient outcomes in the following way: reduction in $\mathrm{HbA} 1 \mathrm{c}$, blood pressure, total cholesterol, LDL, triglycerides, and increase in HDL, as those directions represent an improvement.

- Standard error of effect size $=$

$$
\begin{aligned}
& \sqrt{\mathrm{Sp}^{2}}(1 / \mathrm{Ni}+1 / \mathrm{Nc}) \text { with } \\
& \left.\mathrm{Sp}^{2}=\left[(\mathrm{Ni}-1) \mathrm{Si}^{2}+(\mathrm{Nc}-1) \mathrm{Sc}^{2}\right)\right] / \\
& \quad(\mathrm{Ni}+\mathrm{Nc}-2),
\end{aligned}
$$

where $\mathrm{Ni}$ and $\mathrm{Nc}$ are the intervention and control group sample sizes, respectively, and $\mathrm{Si}$ and $\mathrm{Sc}$ are the intervention and control group sample standard errors (Normand, 1999).
In some included studies interventions were allocated at the clinician or clinic level but data were collected at the patient level. This meant there was some clustering of patients at the clinician (or clinic) level, and adjustment for clustering was required to avoid overstating the significance of differences. In order to deal with the clustering, we calculated an effective sample size for each such study: $N_{\text {effective }}=(k \times m) /$ $[1+(m-1) \times \mathrm{ICC}]$, where $k$ is the number of clusters and $m$ the number of patients per cluster; and ICC refers to the intracluster correlation coefficient (Shojania et al., 2006). We imputed the ICC value as 0.035 based on previous empirical estimations (Campbell et al., 2001).

We used a random-effects meta-analysis to estimate pooled mean effect sizes among included studies. A test for heterogeneity was performed and indicated evidence of statistical heterogeneity (for patient HbA1c results, Cochran's $Q=4341$, $P=0.001)$. The random-effects meta-analysis allows for statistical heterogeneity between studies by assuming that the true effects in the individual studies differ from each other (Normand, 1999).

We used a random-effects meta-regression to formally test whether specific study features influenced the magnitude of the effect sizes across studies. Meta-regression is a useful technique to investigate sources of heterogeneity with respect to clinical diversity (eg, participants and interventions) and methodological diversity (eg, randomization and blinding) of studies. The specific features considered as potentially important sources of clinical and methodological heterogeneity for studies in this review included baseline levels of patient outcomes, study designs (RCTs versus CBAs), methodological quality and the number of intervention components.

Potential publication bias was explored using an inverted funnel plot for patient $\mathrm{HbA} 1 \mathrm{c}$ outcome (Lau et al., 1997). All data analyses were conducted using Stata (version 9.2, College Station, TX, USA).

\section{Results}

\section{Search results}

In all, 615 abstracts were initially identified by electronic and hand search (Figure 2). Of those abstracts, 90 met our explicit inclusion criteria and

Primary Health Care Research \& Development 2008; 9: 25-40 


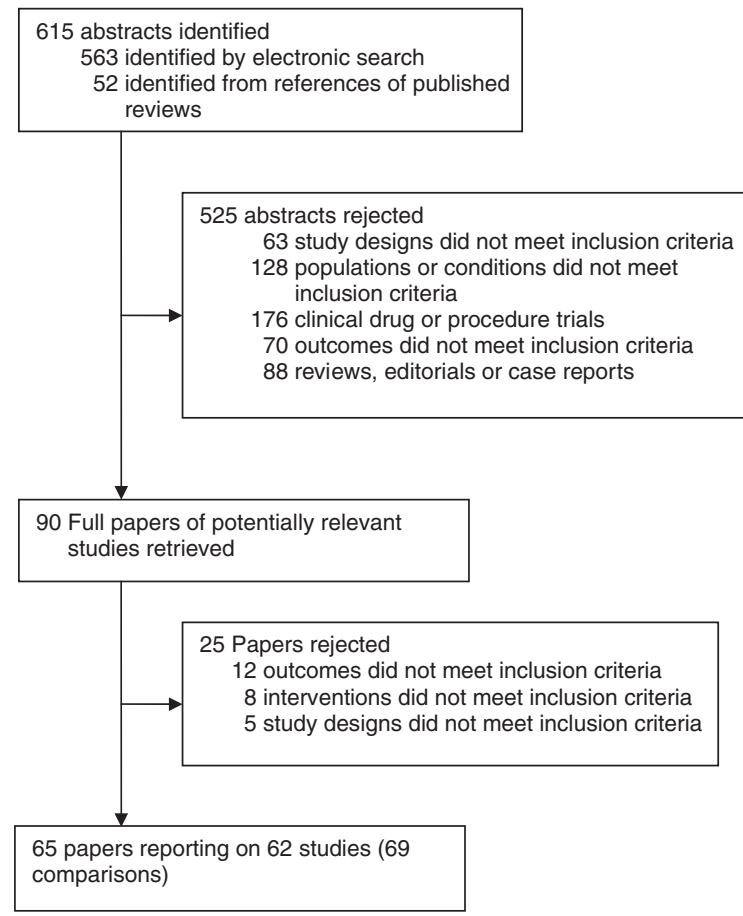

Figure 2 Search results their full-texts were retrieved for data abstraction. During the full-text review, 25 papers failed to meet inclusion criteria and the remaining 65 papers were included for the current review. These 65 papers (listed at the end of this paper) reported 62 studies, with a total of 69 comparisons.

\section{Characteristics of included studies}

Studies conducted in 15 countries were included (Table 2). Nearly half were from the US, followed by the Netherlands and the UK. In all, $18 \%$ of included studies were conducted among selected patients with poor control of diabetes, and $10 \%$ among socioeconomically disadvantaged populations. A total of 39 studies $(63 \%$ of total) were RCTs and 23 (37\%) were CBAs. A detailed summary of each included study is available on request from the authors.

\section{Types and numbers of components used in interventions}

Around half of the included comparisons used decision support, self-management support, delivery system design or clinical information

Table 2 Characteristics of included studies and comparisons ${ }^{a}$

\begin{tabular}{lcc}
\hline Characteristics & $\begin{array}{l}\text { Number (\%) of studies } \\
(n=62)\end{array}$ & $\begin{array}{c}\text { Number (\%) of comparisons } \\
(n=69)\end{array}$ \\
\hline Country & & $34(49 \%)$ \\
US & $30(48 \%)$ & $11(16 \%)$ \\
The Netherlands & $9(15 \%)$ & $7(10 \%)$ \\
UK & $7(11 \%)$ & $3(4 \%)$ \\
Australia & $2(3 \%)$ & $14(21 \%)$ \\
Other countries & $14(23 \%)$ & $12(17 \%)$ \\
Population & $11(18 \%)$ & $7(10 \%)$ \\
Selected patients with poor control & $6(10 \%)$ & $4(6 \%)$ \\
Socioeconomically disadvantaged & & $31(45 \%)$ \\
Year of publication & $2(3 \%)$ & $34(49 \%)$ \\
1980s & $32(52 \%)$ & $1(0.25-9)$ \\
1990s & $28(45 \%)$ & $265(28-22971)$ \\
2000-2004 & $1(0.25-9)$ & $43(62 \%)$ \\
Intervention duration (years), median (range) & - & $26(38 \%)$ \\
Sample size, median (range) & $39(63 \%)$ & \\
Study design & $23(37 \%)$ & \\
RCTs & & \\
CBAs & &
\end{tabular}

${ }^{a}$ Full references of included studies are list at the end of this paper.

RCTs: randomized controlled trials; CBAs: controlled before-and-after studies.

Primary Health Care Research \& Development 2008; 9: 25-40 
Table 3 Types of chronic care model components used in interventions

\begin{tabular}{llccc}
\hline CCM component & $\begin{array}{l}\text { No. of comparisons } \\
\text { RCTs }\end{array}$ & $\begin{array}{l}\text { No. of comparisons } \\
\text { CBAs }\end{array}$ & Combined & $\begin{array}{l}\text { \% of total } \\
(n=69)\end{array}$ \\
\hline Organisational influence & 1 & 2 & 3 & 4 \\
Community linkages & 1 & 1 & 2 & 3 \\
Self-management support & 27 & 8 & 35 & 51 \\
Decision support & 20 & 18 & 31 & 45 \\
Delivery system design & 19 & 12 & 30 & 44 \\
Clinical information systems & 12 & 18 & \\
\hline
\end{tabular}

RCTs: randomized controlled trials; CBAs: controlled before-and-after studies.

Table 4 Effects of different intervention components on $\mathrm{HbA} 1 \mathrm{c}(\%)$ control

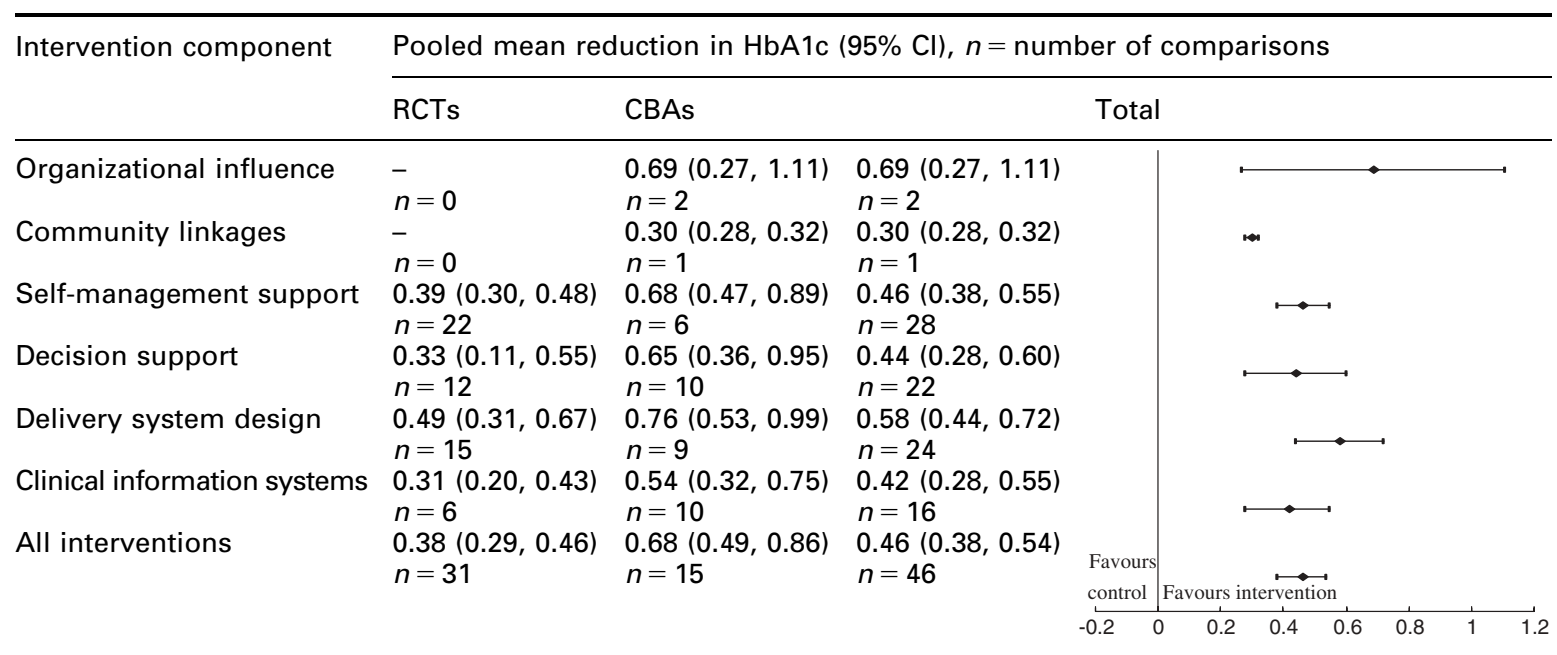

RCTs: randomized controlled trials; CBAs: controlled before-and-after studies.

systems in their interventions (Table 3 ). In contrast, only three comparisons included organizational influence as part of their interventions and two employed community linkages.

In all, $28 \%$ of included studies reported interventions on a single system component, $48 \%$ on two components, and $20 \%$ on three components. The maximum number of components targeted by an intervention was four (4\% of all studies).

\section{Methodological quality}

Overall, the methodological quality of RCTs was more rigorous than that of CBAs. Of the $39 \mathrm{RCTs}$, $23(59 \%)$ were rated as strong in quality, $11(28 \%)$ as moderate and only $5(13 \%)$ as weak. In contrast,
$13 \%$ of CBAs were rated as strong in quality, $39 \%$ as moderate and $49 \%$ as weak in quality.

\section{Impact of different intervention components on diabetes care}

\section{Impact on patient outcomes}

Effects of different intervention components on HbA1c control are shown in Table 4. Forty-six comparisons had sufficient data to allow for calculation of effect sizes in terms of reduction in HbA1c. Overall, the mean reduction in HbA1c was $0.46 \%(95 \%$ CI $0.38,0.54)$. RCTs tended to report smaller effect sizes than CBAs $(0.38 \%$ versus $0.68 \%, P=0.01$ ).

Primary Health Care Research \& Development 2008; 9: 25-40 
Table 5 Effects of interventions on $\mathrm{HbA1c}(\%)$ control by quality of studies

\begin{tabular}{lll}
\hline Intervention component & \multicolumn{2}{l}{ Pooled mean reduction in HbA1c $(95 \% \mathrm{Cl}), n=$ number of comparisons } \\
\cline { 2 - 3 } & Strong quality RCTs $+\mathrm{CBAs}$ & Moderate/weak quality RCTs + CBAs \\
\hline Organisational influence & - & $0.69(0.27,1.11)$ \\
Community linkages & $n=0$ & $n=2$ \\
& - & $0.30(0.28,0.32)$ \\
Self-management support & $n=0$ & $n=1$ \\
& $0.53(0.34,0.72)$ & $0.41(0.32,0.50)$ \\
Decision support & $n=14$ & $n=14$ \\
& $0.47(0.33,0.61)$ & $0.35(0.23,0.47)$ \\
Delivery system design & $n=7$ & $n=15$ \\
& $0.50(0.31,0.69)$ & $0.78(0.49,1.06)$ \\
Clinical information systems & $n=13$ & $n=11$ \\
& $0.41(0.10,0.72)$ & $0.39(0.25,0.53)$ \\
All interventions & $n=5$ & $n=11$ \\
& $0.48(0.33,0.64)$ & $0.44(0.34,0.53)$ \\
& $n=19$ & $n=27$
\end{tabular}

RCTs: randomized controlled trials; CBAs: controlled before-and-after studies.

Studies that included organizational influence reported the greatest reduction in $\mathrm{HbA} 1 \mathrm{c}$ $(0.69 \%)$. It was noted that effect sizes estimated for organizational influence and community linkages were based on only one or two CBAs. Therefore, these findings may be less robust than the estimated mean effect sizes for the other intervention components reflected in a larger number of studies. For this reason, we mainly compared effect sizes among the four practicelevel intervention components.

For the four practice-level intervention components, studies involving delivery system design had the largest reduction in $\mathrm{HbA} 1 \mathrm{c}(0.58 \%)$, followed by those with self-management support $(0.46 \%)$, decision support $(0.44 \%)$ and clinical information systems $(0.42 \%)$.

As shown in Table 5, strong-quality RCTs and CBAs reported a similar reduction in HbA1c when compared with moderate/weakquality RCTs and CBAs $(0.48 \%$ versus $0.44 \%$, $P=0.70)$.

Effects of different intervention components on blood pressure control are shown in Table 6 and Table 7. Twenty-six comparisons had sufficient data to allow for quantitative analysis (25 with both systolic and diastolic results and remaining 1 with systolic results only). Overall, studies reported a mean reduction of systolic (diastolic) blood pressure by $2.2(1.3) \mathrm{mmHg}$. RCTs and CBAs had similar effect sizes $(P>0.7)$. Studies

Primary Health Care Research \& Development 2008; 9: 25-40 with intervention components of delivery system design or self-management support were likely to achieve greater reduction in blood pressure.

Effects of interventions on total cholesterol control are presented in Table 8. A total of 17 comparisons had sufficient data to allow for quantitative analysis. Overall, studies reported a mean reduction of $0.24 \mathrm{mmol} / \mathrm{L}$ in total cholesterol. RCTs and CBAs reported similar effect sizes $(0.21$ versus $0.29, P=0.68)$. Studies with self-management support components had the highest reduction in total cholesterol $(0.32 \mathrm{mmol} / \mathrm{L})$.

A few studies reported the lipid profile in terms of HDL, LDL or triglycerides, and pooled mean effects of relevant parameters are summarized as follows: (1) pooled mean increase in HDL (95\% CI) [number of studies]: $0.02 \mathrm{mmol} / \mathrm{L}$ $(-0.01,0.04)$ [7]; (2) pooled mean reduction in LDL: $0.12(-0.10,0.34)[7]$; and (3) pooled mean reduction in triglycerides: $0.20(0.07,0.32)$ [8].

\section{Associations between study features and effect sizes}

Based on meta-regression analysis, effect sizes (including reduction in $\mathrm{HbA} 1 \mathrm{c}, \mathrm{BP}$ and total cholesterol) did not differ on the basis of baseline levels of patient outcomes, methodological quality (strong versus moderate/weak) or the number of intervention components (multiple versus single). 
Table 6 Effects of different intervention components on systolic BP $(\mathrm{mmHg})$ control

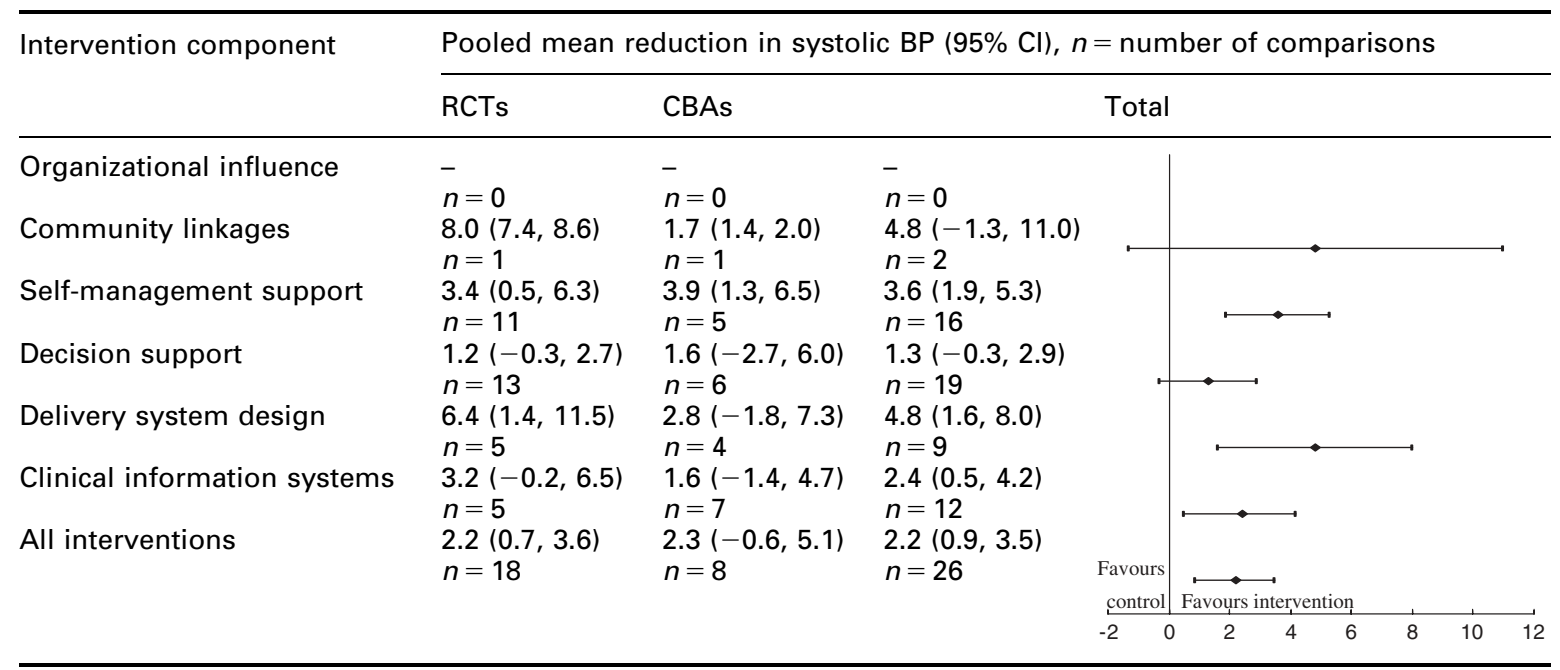

BP: blood pressure; RCTs: randomized controlled trials; CBAs: controlled before-and-after studies.

Table 7 Effects of different intervention components on diastolic BP $(\mathrm{mmHg})$ control

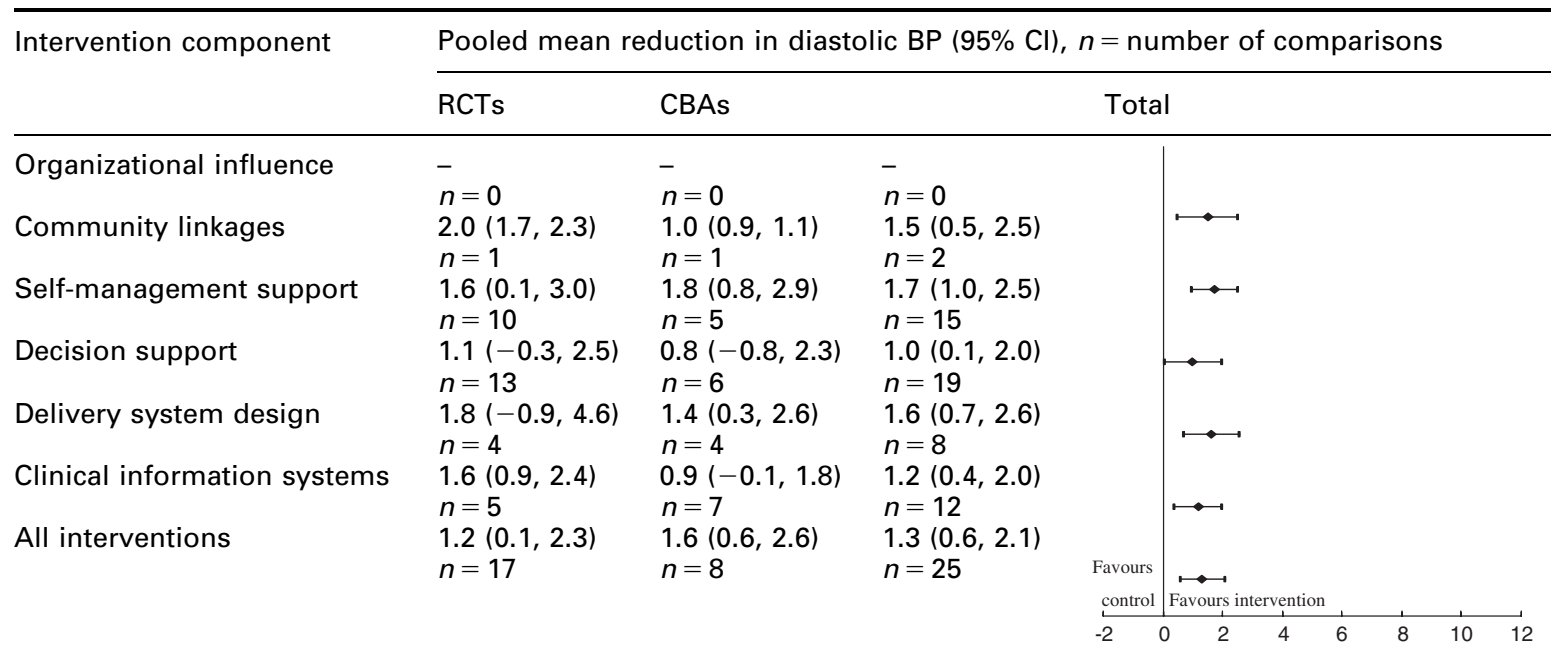

BP: blood pressure; RCTs: randomized controlled trials; CBAs: controlled before-and-after studies.

\section{Publication bias}

The reduction in HbA1c in each study is plotted against the standard error of reduction (Figure 3). The plot shows that, in relation to the estimated mean effect (the vertical line), the numbers of studies are fairly asymmetrical, indicating that some studies with small or negative effect sizes were likely not published.

\section{Discussion}

This review found that the most common $\mathrm{CCM}$ components employed in trials were decision support, self-management support, delivery system design and clinical information systems. The least reported CCM components were organizational influence and community linkages. Most Primary Health Care Research \& Development 2008; 9: 25-40 
Table 8 Effects of different intervention components on total cholesterol ( $\mathrm{mmol} / \mathrm{L}$ ) control

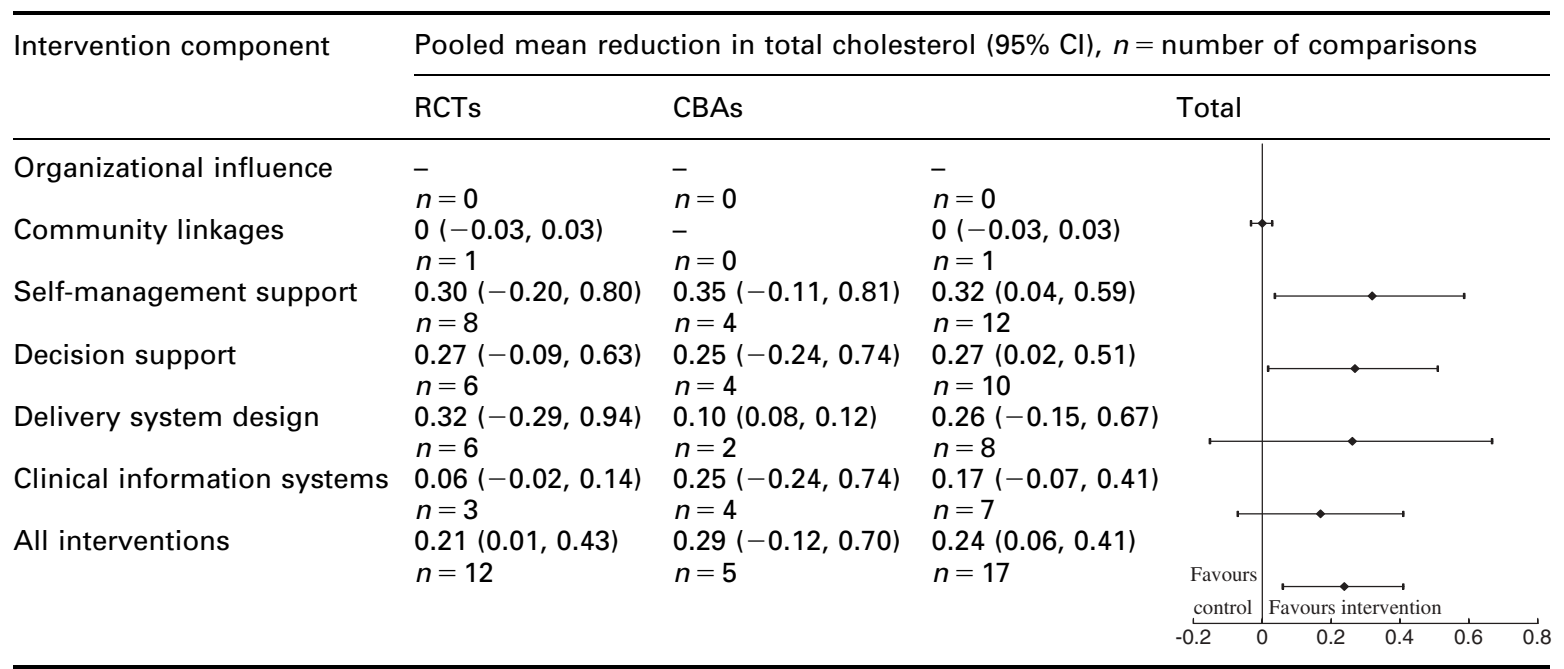

RCTs: randomized controlled trials; CBAs: controlled before-and-after studies.

trials reported using multiple components in their interventions.

Overall, included studies suitable for quantitative analysis reported small-to-moderate, statistically significant improvements in a range of patient intermediate outcomes. For example, there was a mean reduction of $0.46 \%$ in $\mathrm{HbA} 1 \mathrm{c}$, mean reduction of $2.2(1.3) \mathrm{mmHg}$ in systolic (diastolic) blood pressure, and mean reduction of $0.24 \mathrm{mmol} / \mathrm{L}$ in total cholesterol due to interventions as compared to 'usual care'.

For specific CCM components, interventions employing delivery system design reported the largest improvements in patient outcomes, followed by those employing a self-management support component. Interventions involving decision support or clinical information systems reported relatively smaller effect sizes.

\section{Comparison with previous relevant reviews}

Consistent with a previous review (Shojania et al., 2004), this review showed that studies with a randomized controlled design generally reported smaller effect sizes than did studies with a controlled before-after design. However, our data showed that $41 \%$ of the RCTs included in this

Primary Health Care Research \& Development 2008; 9: 25-40

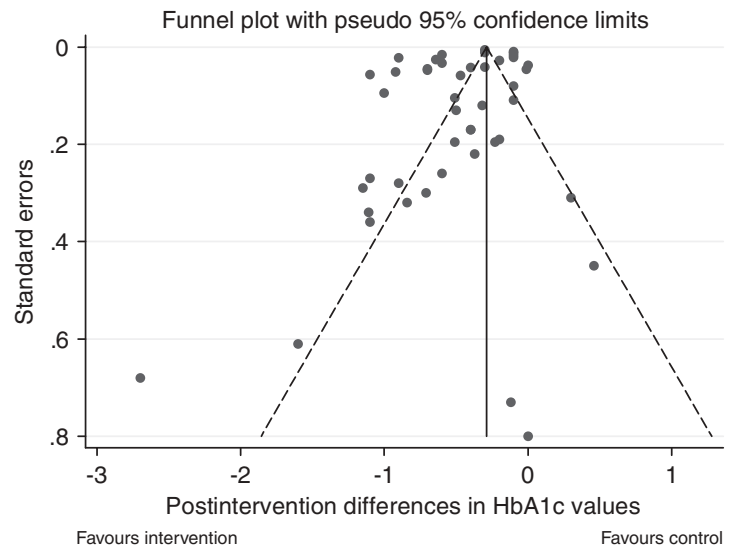

Figure 3 An inverted funnel plot to detect publication bias

reviews were not of high quality, and that $13 \%$ of CBA studies were of high quality. Therefore, it would be useful to report the findings based on high-quality studies, irrespective of RCTs or CBAs. Our further analysis showed that highquality RCTs plus high-quality CBAs reported a similar reduction in $\mathrm{HbA} 1 \mathrm{c}$ as compared with moderate/low-quality RCTs and CBAs $(0.48 \%$ 
versus $0.44 \%)$. This mean effect size $(0.48 \%)$ reported by high-quality studies tended to be greater than that reported by RCTs $(0.38 \%)$, but was smaller than that reported by CBAs $(0.68 \%)$. Effect sizes based on high-quality studies are likely to be closer to true effect sizes than those from low-quality studies.

Greater benefit of multiple interventions over single-facet interventions has been suggested by a meta-analysis of disease management programmes for patients with chronic illness (Weingarten et al., 2002). However, our metaregression analysis showed that effect sizes did not differ between interventions targeting multiple CCM components and those involving a single component. Plausibly, intensity of the interventions (instead of the number of intervention components) may have an impact on the effect sizes. However, we were unable to explore this relationship due to the lack of explicit description of intervention intensity from the original studies.

Our review highlighted delivery system design as one of the most important intervention components in achieving improvements in diabetes care. Delivery system design included an emphasis on role definitions for different professionals, patient care planning and regular followup, and coordination between primary care and specialist services. In a Cochrane review of diabetes care (Renders et al., 2001), Renders and colleagues reported that multiple interventions in which the role of the nurse in the follow-up of patients was enhanced had favourable effects on patient outcomes. In a systematic review assessing the effectiveness of disease management (defined as organized, proactive and integrated health care delivery that focused on the entire spectrum of the disease and its complications, and consistent with our definition of delivery system design) on diabetes care, Norris et al. (2002b) reported that disease management interventions achieved a net reduction of $0.5 \%$ in $\mathrm{HbA} 1 \mathrm{c}$ (corresponding figure in our review is $0.58 \%$ ).

The effectiveness of self-management training interventions on diabetes care has been reported in previously published reviews (Norris et al., 2001; 2002a). In their reviews, Norris et al. (2002a) included interventions exclusively focusing on selfmanagement training (education). With a median intervention duration of 6 months, included studies reported an average reduction of $0.76 \%$ in $\mathrm{HbA} 1 \mathrm{c}$ during or immediately after the intervention. However, this effect size shrank to $0.26 \%$ four or more months after the intervention ceased. Furthermore, effects of self-management training on blood pressure and lipid control were inconsistent (Norris et al., 2001). Considering that, in our review, a reduction of $0.46 \%$ in HbA1c was reported by studies using self-management support as part of multi-component interventions (with a median duration of 1 year), it appears that incorporating self-management support into other intervention components is more likely to achieve sustained improvement in diabetes care.

The review by Zwar et al. (2006) discussing the impact of interventions using the CCM components on a range of chronic disease showed the evidence to be largely focused on diabetes care, with relatively few studies of the impact on other chronic diseases. Their findings of the impact of interventions that addressed delivery system design and self-management support are consistent with our review findings. However, their review did not incorporate the research evidence on organizational influence and community linkages as has been done in our review. This may reflect a different approach to defining these two CCM components, and highlights the need for clearer conceptualization and description of these components on further research.

\section{Strengths and limitations of the present review}

The impact of different interventions on diabetes care was assessed in terms of patient intermediate outcomes. We examined HbA1c, blood pressure and blood lipid control simultaneously, to reflect advances in scientific knowledge that control of blood pressure and blood lipids for diabetes patients is as important as, if not more important than, control of $\mathrm{HbA} 1 \mathrm{c}$ in reducing micro- and macro-vascular complications (Williams et al., 2002); most other reviews have evaluated only patients' HbA1c control (Weingarten et al., 2002; Norris et al., 2002a; 2002b; Shojania et al., 2004).

This review has several limitations. First, only one reviewer screened search results and extracted data for this review, and the process was repeated to increase the reliability of data extraction. However, the 'gold standard' is to have two reviewers doing this independently. Second, due to

Primary Health Care Research \& Development 2008; 9: 25-40 
complexity of the interventions and lack of detailed description in some studies, there was potential for misclassification of interventions in relation to the CCM components. Third, many studies provided insufficient detail in the method sections for us to understand the intensity of the interventions. For example, a study might report that patient self-management education was used, but provide insufficient information on the frequency of engagement with participants and the type of process and materials used. Fourth, this review only indicates the relative effectiveness of different intervention components, and the absolute effect attributable to a particular component remains unknown, as most included studies employed multi-component interventions. Last, this review found that interventions featuring the CCM components had little effect on blood pressure control. This finding may not reflect the true effect, because studies considered in this review were selected on the basis of an intervention primarily against diabetes rather than hypertension, and the blood pressure outcomes may have been secondary compared to the primary outcome of glycaemic control. It would be useful to perform a similar systematic review of the effectiveness of CCMoriented interventions on hypertension control.

\section{Reviewer's conclusions}

\section{Implications for practice}

Overall, the findings support the concept of the CCM in which the state of development of various aspects of primary care service systems defined in this model appears to be important factors in the quality of care provided to people with diabetes.

\section{Implications for research}

Further studies need to describe in sufficient detail the type and dose of interventions used, to enable others to understand and replicate them in different settings. Importantly, studies providing information on factors that facilitate or inhibit implementation of interventions are particularly useful, as such factors can be incorporated into future intervention designs.

There is also a need for more research to be conducted among diabetes patients from poorer

Primary Health Care Research \& Development 2008; 9: 25-40 socioeconomic backgrounds, who generally experience higher morbidity and mortality due to diabetes. Of the studies included in this review, only six were conducted in socioeconomically disadvantaged populations, and only one was conducted in an Australian Indigenous setting (McDermott et al., 2001), highlighting the lack of studies with direct applicability to disadvantaged populations in specific settings.

The small number of studies of interventions addressing organizational influence and community linkages provides less certainty on the benefits associated with those components. However, given the fact that studies that included organizational influence in interventions reported superior reduction in $\mathrm{HbA} 1 \mathrm{c}(0.69 \%)$, this system component may be of considerable importance to accelerate improvements in chronic illness care. There is a need for further research to determine the significance of this component of the CCM.

\section{Acknowledgements}

DS's work is supported by an NHMRC Population Health Capacity Building Grant (\#236235). RB's work is supported by an NHMRC Senior Research Fellowship (\#283303).

\section{References}

Bodenheimer, T., Wagner, E.H. and Grumbach, K. 2002: Improving primary care for patients with chronic illness: the chronic care model, Part 2. JAMA 288, 1909-914.

Bonomi, A.E., Wagner, E.H., Glasgow, R.E. and VonKorff, M. 2002: Assessment of chronic illness care (ACIC): a practical tool to measure quality improvement. Health Services Research 37, 791-820.

Campbell, M.K., Mollison, J. and Grimshaw, J.M. 2001: Cluster trials in implementation research: estimation of intracluster correlation coefficients and sample size. Statistics in Medicine 20, 391-99.

Cochrane Effective Practice and Organisation of Care Group. EPOC MEDLINE and HealthSTAR Search Strategy. http://www.epoc.uottawa.ca/register.htm. 2004.

Cochrane Effective Practice and Organisation of Care Group. Study designs for EPOC reviews. http://www.epoc.uottawa. ca/FAQIncludedStudies.doc. 2006.

Cochrane Metabolic and Endocrine Disorders Group. Search strategies. Resources for reviewers. http://www.cc-endoc. info/. 21-7-2003. 
Effective Public Health Practice Project. Effective Public Health Practice Project. http://www.myhamilton.ca/ myhamilton/CityandGovernment/HealthandSocialServices/ Research/EPHPP/. 2006.

Epping-Jordan, J.E., Pruitt, S.D., Bengoa, R. and Wagner, E.H. 2004: Improving the quality of health care for chronic conditions. Quality and Safety in Health Care 13, 299-305.

Fulton, T.R., Penney, B.C. and Taft, A. 2001: Exploring a chronic care model in a regional healthcare context. Healthcare Management Forum 14, 6-24.

Giuffrida, A., Gosden, T., Forland, F., Kristiansen, I.S., Sergison, M., Leese, B., Pedersen, L. and Sutton, M. 1999: Target payments in primary care: effects on professional practice and health care outcomes. The Cochrane Database of Systematic Reviews 1999, Issue 4. Art. No.: CD000531. DOI:10.1002/14651858.CD000531.

Griffiths, C., Taylor, S., Feder, G., Candy, B., Ramsay, J., Eldridge, S. and Barlow, J. 2005: Self management education by lay leaders for people with chronic conditions. The Cochrane Database of Systematic Reviews 2005, Issue 1. Art. No.: CD005108. DOI:10.1002/14651858.CD005108.

Landon, B.E., Hicks, L.S., O'Malley, A.J., Lieu, T.A., Keegan, T., McNeil, B.J. and Guadagnoli, E. 2007: Improving the Management of Chronic Disease at Community Health Centers. The New England Journal of Medicine 356, 921-34.

Lau, J., Ioannidis, J.P.A. and Schmid, C.H. 1997: Quantitative synthesis in systematic reviews. Annals of Internal Medicine 127, 820-26.

Lewis, R. and Dixon, J. 2004: Rethinking management of chronic diseases. British Medical Journal 328, 220-22.

McDermott, R.A., Schmidt, B.A., Sinha, A. and Mills, P. 2001: Improving diabetes care in the primary healthcare setting: a randomised cluster trial in remote Indigenous communities. Medical Journal of Australia 174, 497-502.

Normand, S.L. 1999: Meta-analysis: formulating, evaluating, combining, and reporting. Statistics in Medicine 18, 321-59.

Norris, S.L., Engelgau, M.M. and Venkat Narayan, K.M. 2001: Effectiveness of self-management training in type 2 diabetes: a systematic review of randomized controlled trials. Diabetes Care 24, 561-87.

Norris, S.L., Lau, J., Smith, S.J., Schmid, C.H. and Engelgau, M.M. 2002a: Self-management education for adults with type 2 diabetes: a meta-analysis of the effect on glycemic control. Diabetes Care 25, 1159-171.

Norris, S.L., Nichols, P.J., Caspersen, C.J., Glasgow, R.E., Engelgau, M.M., Jack, J., Isham, G., Snyder, S.R. and Carande-Kulis, V.G. 2002b: The effectiveness of disease and case management for people with diabetes: A systematic review. American Journal of Preventive Medicine $22,15-38$.

Piatt, G.A., Orchard, T.J., Emerson, S., Simmons, D., Songer, T.J., Brooks, M.M., Korytkowski, M., Siminerio, L.M., Ahmad, U. and Zgibor, J.C. 2006: Translating the chronic care model into the community: results from a randomized controlled trial of a multifaceted diabetes care intervention. Diabetes Care 29, 811-17.

Renders, C.M., Valk, G.D., Griffin, S., Wagner, E.H., Eijk, J.T. and Assendelft, W.J. 2001: Interventions to improve the management of diabetes mellitus in primary care, outpatient and community settings. The Cochrane Database of Systematic Reviews 2001, Issue 1. Art. No.: CD001481. DOI:10.1002/14651858.CD001481.

Roger, S. 2004: Continuous quality improvement: effects on professional practice and patient outcomes (Protocol for a Cochrane Review). Chichester, UK: John Wiley \& Sons, Ltd.

Shojania, K.G., Ranji, S.R., Shaw, L.K., Charo, L.N., Lai, J.C., Rushakoff, R.J., McDonald, K.M. and Owens, D.K. 2004: Closing the quality gap: a critical analysis of quality improvement strategies - Volume 2: diabetes mellitus care. Rockville, MD: Agency for Healthcare Research and Quality.

Shojania, K.G., Ranji, S.R., McDonald, K.M., Grimshaw, J.M., Sundaram, V., Rushakoff, R.J. and Owens, D.K. 2006: Effects of quality improvement strategies for type 2 diabetes on glycemic control: a meta-regression analysis. JAMA 296, 427-40.

Sperl-Hillen, J.M., Solberg, L.I., Hroscikoski, M.C., Crain, A.L., Engebretson, K.I. and O'Connor, P.J. 2004: Do all components of the chronic care model contribute equally to quality improvement? Joint Commission Journal on Quality and Safety 30, 303-09.

Wagner, E.H. 1998: Chronic disease management: what will it take to improve care for chronic illness? Effective Clinical Practice 1, 2-4.

Wagner, E.H., Austin, B.T. and Von Korff, M. 1996: Organizing care for patients with chronic illness. Milbank Quarterly 74, 511-44.

Wagner, E.H., Davis, C., Schaefer, J., Von Korff, M. and Austin, B. 1999: A survey of leading chronic disease management programs: are they consistent with the literature? Managed Care Quarterly 7, 56-66.

Wagner, E.H., Austin, B.T., Davis, C., Hindmarsh, M., Schaefer, J. and Bonomi, A. 2001a: Improving chronic illness care: translating evidence into action. Health Affairs (Millwood) 20, 64-78.

Wagner, E.H., Glasgow, R.E., Davis, C., Bonomi, A.E., Provost, L., McCulloch, D., Carver, P. and Sixta, C. 2001b: Quality improvement in chronic illness care: a collaborative approach. Joint Commission Journal on Quality Improvement 27, 63-80.

Weingarten, S.R., Henning, J.M., Badamgarav, E., Knight, K., Hasselblad, V., Gano, Jr. A. and Ofman, J.J. 2002: Interventions used in disease management programmes for patients with chronic illness-which ones work? Metaanalysis of published reports. British Medical Journal 325, 925.

Williams, R., Herman, W., Kinmonth, A.L. and Wareham, N.J. 2002: The evidence base for diabetes care. Chichester: John Wiley \& Sons, Ltd.

Primary Health Care Research \& Development 2008; 9: 25-40 
Wu, S., Pearson, M., Schaefer, J., Bonomi, A.E., Shortell, S.M., Mendel, P.J., Marsteller, J.A., Louis, T.A. and Keeler, E.B. 2003: Assessing the implementation of the chronic care model in quality improvement collaboratives: does baseline system support for chronic care matter? In H. Luczak, K.J. Zink, and H. Luxzak, editors, Human factors in organizational design and management-VII, First edition. Santa Monica: IEA Press, pp. 595-601.

Zwar, N., Harris, M., Griffiths, R., Roland, M., Dennis, S., Powell Davies, G. and Hasan, I. 2006: A systematic review of chronic disease management. Sydney: Research Centre for Primary Health Care and Equity, School of Public Health and Community Medicine, University of New South Wales.

\section{Reference list of studies included in this review}

Aubert, R.E., Herman, W.H., Waters, J., Moore, W., Sutton, D., Peterson, B.L., Bailey, C.M. and Koplan, J.P. 1998: Nurse case management to improve glycemic control in diabetic patients in a health maintenance organization. A randomized, controlled trial. Annals of Internal Medicine 129, 605-12.

Benjamin, E.M., Schneider, M.S. and Hinchey, K.T. 1999: Implementing practice guidelines for diabetes care using problem-based learning. A prospective controlled trial using firm systems. Diabetes Care 22, 1672-678.

Branger, P.J., van't Hooft, A., van der Wouden, J.C., Moorman, P.W. and van Bemmel, J.H. 1999: Shared care for diabetes: supporting communication between primary and secondary care. International Journal of Medical Informatics 53, 133-42.

Carlson, A. and Rosenqvist, U. 1991: Diabetes care organization, process, and patient outcomes: effects of a diabetes control program. Diabetes Educator 17, 42-48.

Clancy, D.E., Brown, S.B., Magruder, K.M. and Huang, P. 2003: Group visits in medically and economically disadvantaged patients with type 2 diabetes and their relationships to clinical outcomes. Topics in Health Information Management 24, 8-14.

de Sonnaville, J.J., Bouma, M., Colly, L.P., Deville, W., Wijkel, D. and Heine, R.J. 1997: Sustained good glycaemic control in NIDDM patients by implementation of structured care in general practice: 2-year follow-up study. Diabetologia 40, 1334-340.

de, W.I., Visser, A.P., Kok, G.J., de Weerdt, O. and van der Veen, E.A. 1991: Randomized controlled multicentre evaluation of an education programme for insulintreated diabetic patients: effects on metabolic control, quality of life, and costs of therapy. Diabetic Medicine 8, 338-45.

Deeb, L.C., Pettijohn, F.P., Shirah, J.K. and Freeman, G. 1988: Interventions among primary-care practitioners to improve care for preventable complications of diabetes. Diabetes Care 11, 275-80.

Primary Health Care Research \& Development 2008; 9: 25-40
Diabetes Integrated Care Evaluation Team. 1994: Integrated care for diabetes: clinical, psychosocial, and economic evaluation. Diabetes Integrated Care Evaluation Team. British Medical Journal 308, 1208-212.

Domenech, M.I., Assad, D., Mazzei, M.E., Kronsbein, P. and Gagliardino, J.J. 1995: Evaluation of the effectiveness of an ambulatory teaching/treatment programme for non-insulin dependent (type 2) diabetic patients. Acta Diabetologica 32, 143-47.

Feder, G., Griffiths, C., Highton, C., Eldridge, S., Spence, M. and Southgate, L. 1995: Do clinical guidelines introduced with practice based education improve care of asthmatic and diabetic patients? A randomised controlled trial in general practices in east London. British Medical Journal 311, 1473-478.

Gaede, P., Vedel, P., Larsen, N., Jensen, G.V.H., Parving, H.H. and Pedersen, O. 2003: Multifactorial intervention and cardiovascular disease in patients with type 2 diabetes. The New England Journal of Medicine 348, 383-93.

Gaede, P., Vedel, P., Parving, H.H. and Pedersen, O. 1999: Intensified multifactorial intervention in patients with type 2 diabetes mellitus and microalbuminuria: the Steno type 2 randomised study. Lancet 353, 617-22.

Glasgow, R.E., Toobert, D.J. and Hampson, S.E. 1996: Effects of a brief office-based intervention to facilitate diabetes dietary self-management. Diabetes Care 19, 835.

Goudswaard, A.N., Stolk, R.P., Zuithoff, N.P., de Valk, H.W. and Rutten, G.E. 2004: Long-term effects of self-management education for patients with Type 2 diabetes taking maximal oral hypoglycaemic therapy: a randomized trial in primary care. Diabetic Medicine 21, 491-96.

Grant, R.W., Hamrick, H.E., Sullivan, C.M., Dubey, A.K., Chueh, H.C., Cagliero, E. and Meigs, J.B. 2003: Impact of population management with direct physician feedback on care of patients with type 2 diabetes. Diabetes Care 26, 2275-280.

Groeneveld, Y., Petri, H., Hermans, J. and Springer, M. 2001: An assessment of structured care assistance in the management of patients with type 2 diabetes in general practice. Scandinavian Journal of Prim Health Care 19, 25-30.

Guerci, B., Drouin, P., Grange, V., Bougneres, P., Fontaine, P., Kerlan, V., Passa, P., Thivolet, C., Vialettes, B., Charbonnel, B. and ASIA Group. 2003: Self-monitoring of blood glucose significantly improves metabolic control in patients with type 2 diabetes mellitus: the AutoSurveillance Intervention Active (ASIA) study. Diabetes \& Metabolism 29, 587-94.

Halbert, R.J., Leung, K.M., Nichol, J.M. and Legorreta, A.P. 1999: Effect of multiple patient reminders in improving diabetic retinopathy screening. A randomized trial. Diabetes Care 22, 752-55.

Hetlevik, I., Holmen, J., Kruger, O., Kristensen, P., Iversen, H. and Furuseth, K. 2000: Implementing clinical guidelines in the treatment of diabetes mellitus in general practice. Evaluation of effort, process, and patient outcome related to implementation of a computer-based decision support 
system. International Journal of Technology Assessment in Health Care 16, 210-27.

Hirsch, I.B., Goldberg, H.I., Ellsworth, A., Evans, T.C., Herter, C.D., Ramsey, S.D., Mullen, M., Neighbor, W.E. and Cheadle, A.D. 2002: A multifaceted intervention in support of diabetes treatment guidelines: a cont trial. Diabetes Research and Clinical Practice 58, 27-36.

Hoskins, P.L., Fowler, P.M., Constantino, M., Forrest, J., Yue, D.K. and Turtle, J.R. 1993: Sharing the care of diabetic patients between hospital and general practitioners: does it work? Diabetic Medicine 10, 81-86.

Hurwitz, B., Goodman, C. and Yudkin, J. 1993: Prompting the clinical care of non-insulin dependent (type II) diabetic patients in an inner city area: one model of community care. British Medical Journal 306, 624-30.

Ilag, L.L., Martin, C.L., Tabaei, B.P., Isaman, D.J., Burke, R., Greene, D.A. and Herman, W.H. 2003: Improving diabetes processes of care in managed care. Diabetes Care 26, 2722-727.

Kinmonth, A.L., Woodcock, A., Griffin, S., Spiegal, N. and Campbell, M.J. 1998: Randomised controlled trial of patient centred care of diabetes in general practice: impact on current wellbeing and future disease risk. The Diabetes Care From Diagnosis Research Team. British Medical Journal 317, 1202-208.

Lafata, J.E., Baker, A.M., Divine, G.W., McCarthy, B.D. and Xi, H. 2002: The use of computerized birthday greeting reminders in the management of diabetes. Journal of General Internal Medicine 17, 521-30.

Legorreta, A.P., Peters, A.L., Ossorio, R.C., Lopez, R.J., Jatulis, D. and Davidson, M.B. 1996: Effect of a comprehensive nurse-managed diabetes program: an HMO prospective study. American Journal of Managed Care 2, 1024-030.

Levetan, C.S., Dawn, K.R., Robbins, D.C. and Ratner, R.E. 2002: Impact of computer-generated personalized goals on HbA1c. Diabetes Care 25, 2-8.

Lim, F.S., Toh, M.P., Emmanuel, S.C. and Chan, S.P. 2002: A preliminary evaluation of a disease management programme for patients with diabetes mellitus and hypertension in a primary healthcare setting. Annals of the Academy of Medicine, Singapore 31, 431-39.

Litzelman, D.K., Slemenda, C.W., Langefeld, C.D., Hays, L.M., Welch, M.A., Bild, D.E., Ford, E.S. and Vinicor, F. 1993: Reduction of lower extremity clinical abnormalities in patients with non-insulin-dependent diabetes mellitus. A randomized, controlled trial. Annals of Internal Medicine 119, 36-41.

Lobach, D.F. and Hammond, W.E. 1997: Computerized decision support based on a clinical practice guideline improves compliance with care standards. American Journal of Medicine 102, 89-98.

Mazzuca, S.A., Vinicor, F., Cohen, S.J., Norton, J.A., Fineberg, N.S., Fineberg, S.E., Duckworth, W.C., Kuebler, T.W., Gordon, E.E. and Clark, Jr. C.M. 1988: The Diabetes Education Study: a controlled trial of the effects of intensive instruction of internal medicine residents on the management of diabetes mellitus. Journal of General Internal Medicine 3, 1-8.

McClellan, W.M., Millman, L., Presley, R., Couzins, J. and Flanders, W.D. 2003: Improved diabetes care by primary care physicians: results of a group-randomized evaluation of the Medicare Health Care Quality Improvement Program (HCQIP). Journal of Clinical Epidemiology 56, 1210-217.

McDermott, R.A., Schmidt, B.A., Sinha, A. and Mills, P. 2001: Improving diabetes care in the primary healthcare setting: a randomised cluster trial in remote Indigenous communities. Medical Journal of Australia 174, 497-502.

Meigs, J.B., Cagliero, E., Dubey, A., Murphy-Sheehy, P., Gildesgame, C., Chueh, H., Barry, M.J., Singer, D.E. and Nathan, D.M. 2003: A controlled trial of web-based diabetes disease management: the MGH diabetes primary care improvement project. Diabetes Care 26, 750-57.

Mitchell, E., McConnahie, A. and Sullivan, F. 2003: Consultation computer use to improve management of chronic disease in general practice: a before and after study. Informatics in Primary Care 11, 61-68.

O'Connor, P.J., Rush, W.A., Peterson, J., Morben, P., Cherney, L., Keogh, C. and Lasch, S. 1996: Continuous quality improvement can improve glycemic control for HMO patients with diabetes. Archives of Family Medicine 5, 502-06.

Olivarius, N.F., Beck-Nielsen, H., Andreasen, A.H., Horder, M. and Pedersen, P.A. 2001: Randomised controlled trial of structured personal care of type 2 diabetes mellitus. British Medical Journal 323, 970-75.

Ovhed, I., Johansson, E., Odeberg, H. and Rastam, L. 2000: A comparison of two different team models for treatment of diabetes mellitus in primary care. Scandinavian Journal of Caring Sciences 14, 253-58.

Peters, A.L. and Davidson, M.B. 1998: Application of a diabetes managed care program. The feasibility of using nurses and a computer system to provide effective care. Diabetes Care 21, 1037-043.

Pieber, T.R., Holler, A., Siebenhofer, A., Brunner, G.A., Semlitsch, B., Schattenberg, S., Zapotoczky, H., Rainer, W. and Krejs, G.J. 1995: Evaluation of a structured teaching and treatment programme for type 2 diabetes in general practice in a rural area of Austria. Diabetic Medicine 12, 349-54.

Piette, J.D., Weinberger, M., Kraemer, F.B. and McPhee, S.J. 2001: Impact of automated calls with nurse follow-up on diabetes treatment outcomes in a Department of Veterans Affairs Health Care System: a randomized controlled trial. Diabetes Care 24, 202-08.

Piette, J.D., Weinberger, M., McPhee, S.J., Mah, C.A., Kraemer, F.B. and Crapo, L.M. 2000: Do automated calls with nurse follow-up improve self-care and glycemic control among vulnerable patients with diabetes? The American Journal of Medicine 108, 20-27.

Pill, R., Stott, N.C., Rollnick, S.R. and Rees, M. 1998: A randomized controlled trial of an intervention designed

Primary Health Care Research \& Development 2008; 9: 25-40 
to improve the care given in general practice to Type II diabetic patients: patient outcomes and professional ability to change behaviour. Family Practice 15, 229-35.

Reed, R.L., Revel, A.O., Carter, A., Saadi, H.F. and Dunn, E.V. 2001: A clinical trial of chronic care diabetic clinics in general practice in the United Arab Emirates: a preliminary analysis. Archives of Physiology and Biochemistry 109, 272-80.

Renders, C.M., Valk, G.D., de Sonnaville, J.J., Twisk, J., Kriegsman, D.M., Heine, R.J., van Eijk, J.T. and van der, W.G. 2003: Quality of care for patients with Type 2 diabetes mellitus-a long-term comparison of two quality improvement programmes in the Netherlands. Diabetic Medicine 20, 846-52.

Renders, C.M., Valk, G.D., Franse, L.V., Schellevis, F.G., van Eijk, J.T. and van der, W.G. 2001: Long-term effectiveness of a quality improvement program for patients with type 2 diabetes in general practice. Diabetes Care 24, 1365-370.

Ridgeway, N.A., Harvill, D.R., Harvill, L.M., Falin, T.M., Forester, G.M. and Gose, O.D. 1999: Improved control of type 2 diabetes mellitus: a practical education/behavior modification program in a primary care clinic. Southern Medical Journal 92, 667-72.

Rothman, R.L., DeWalt, D.A., Malone, R., Bryant, B., Shintani, A., Crigler, B., Weinberger, M. and Pignone, M. 2004: Influence of patient literacy on the effectiveness of a primary care-based diabetes disease management program. JAMA 292, 1711-716.

Rutten, G., van Eijk, J., de Nobel, E., Beek, M. and van d, V. 1990: Feasibility and effects of a diabetes type II protocol with blood glucose self-monitoring in general practice. Family Practice 7, 273-78.

Sadur, C.N., Moline, N., Costa, M., Michalik, D., Mendlowitz, D., Roller, S., Watson, R., Swain, B.E., Selby, J.V. and Javorski, W.C. 1999: Diabetes management in a health maintenance organization. Efficacy of care management using cluster visits. Diabetes Care 22, 2011-017.

Schmidt, S.O., Burns, C., Feller, D.B., Chang, K.L., Hernandez, B., McCarthy, J. and Burg, M.A. 2003: Evaluation of a quality improvement intervention for diabetes management. Journal for Healthcare Quality 25, 26-32.

Simmons, D., Gamble, G.D., Foote, S., Cole, D.R., Coster, G. and New Zealand Diabetes Passport Study. 2004: The New Zealand Diabetes Passport Study: a randomized controlled trial of the impact of a diabetes passport on risk factors for diabetes-related complications. Diabetic Medicine 21, 214-17.

Smith, S., Bury, G., O'Leary, M., Shannon, W., Tynan, A., Staines, A. and Thompson, C. 2004: The North Dublin randomized controlled trial of structured diabetes shared care. Family Practice 21, 39-45.

Smith, S.A., Murphy, M.E., Huschka, T.R., Dinneen, S.F., Gorman, C.A., Zimmerman, B.R., Rizza, R.A. and Naessens, J.M. 1998: Impact of a diabetes electronic management system on the care of patients seen in a subspecialty diabetes clinic. Diabetes Care 21, 972-76.

Sutherland, J.E., Hoehns, J.D., O’Donnell, B. and Wiblin, R.T. 2001: Diabetes management quality improvement in a family practice residency program. Journal of the American Board of Family Practice 14, 243-51.

Thompson, D.M., Kozak, S.E. and Sheps, S. 1999: Insulin adjustment by a diabetes nurse educator improves glucose control in insulin-requiring diabetic patients: a randomized trial. Canadian Medical Association Journal 161, 959-62.

Varroud-Vial, M., Simon, D., Attali, J., Durand-Zaleski, I., Bera, L., Attali, C., Letondeur, C., Strauss, K., Petit, C. and Charpentier, G. 2004: Improving glycaemic control of patients with Type 2 diabetes in a primary care setting: a French application of the Staged Diabetes Management programme. Diabetic Medicine 21, 592-98.

Vaughan, N.J. and Potts, A. 1996: Implementation and evaluation of a decision support system for type II diabetes. Computer Methods \& Programs in Biomedicine 50, 247-51.

Vinicor, F., Cohen, S.J., Mazzuca, S.A., Moorman, N., Wheeler, M., Kuebler, T., Swanson, S., Ours, P., Fineberg, S.E. and Gordon, E.E. 1987: DIABEDS: a randomized trial of the effects of physician and/or patient education on diabetes patient outcomes. Journal of Chronic Diseases 40, 345-56.

Wagner, E.H., Grothaus, L.C., Sandhu, N., Galvin, M.S., McGregor, M., Artz, K. and Coleman, E.A. 2001: Chronic care clinics for diabetes in primary care: a system-wide randomized trial. Diabetes Care 24, 695-700.

Weinberger, M., Kirkman, M.S., Samsa, G.P., Shortliffe, E.A., Landsman, P.B., Cowper, P.A., Simel, D.L. and Feussner, J.R. 1995: A nurse-coordinated intervention for primary care patients with non-insulin-dependent diabetes mellitus: impact on glycemic control and health-related quality of life. Journal of General Internal Medicine 10, 59-66.

Whitlock, W.L., Brown, A., Moore, K., Pavliscsak, H., Dingbaum, A., Lacefield, D., Buker, K., Xenakis, S., Buker, K. and Xenakis, S. 2000: Telemedicine improved diabetic management. Military Medicine 165, 579-84.

Wong, T.Y., Ho, H.K., Lim, C., Tan, B.Y., Lim, F.S. and Emmanuel, S.C. 2003: Comparative study of a two-year disease management programme for patients with diabetes in a primary healthcare setting. Annals of the Academy of Medicine, Singapore 32, S73-75. 